\title{
Sosialisasi Peraturan Daerah Sempadan Sungai Dalam Rangka Pengendalian Bajir Sungai Maros
}

\author{
Rita Lopa*, Farouk Maricar, Saleh Pallu, Arsyad Thaha ,Bambang Bakri, Farid Maricar, Ahmad \\ Sumakin, Mukhsan Hatta, Silman Pongmanda, Riswal Karamma, Subhan Mustari, Ildha Dwi \\ Puspita dan Ilham
}

Departemen Teknik Sipil, Fakultas Teknik, Universitas Hasanuddin ritalopa@unhas.ac.id*

\begin{abstract}
Abstrak
Kabupaten Maros merupakan salah satu kabupaten di Provinsi Sulawesi Selatan yang sistem pengelolaan sungainya belum maksimal. Berdasarkan hal ini, maka permasalahan banjir Sungai Maros di Kabupaten Maros harus ditangani sesegera mungkin dengan cara yang baik dan benar serta diperlukan partisipasi masyarakat dalam hal pemahaman peraturan daerah sempadan sungai. Tujuan kegiatan ini adalah memberikan sosialisasi kepada masyarakat untuk meningkatkan pengetahuan masyarakat tentang peraturan daerah sempadan sungai. Metode yang digunakan untuk mencapai tujuan dan target yang telah ditetapkan adalah dengan cara melaksanakan sekolah sungai yang diharapkan berguna bagi masyarakat setempat. Kegiatan yang dilakukan akan melibatkan dan mengikut sertakan masyarakat. Terlaksananya kegiatan pengabdian ini, berupa sosialisasi peraturan daerah sempadan sungai dalam rangka pengendalian banjir maka diharapkan pengetahuan masyarakat mengenai sempadan sungai akan meningkat dan pola prilaku masyarakat mengenai penanganan daerah sempadan sungai dapat ditingkatkan dan akan memberikan dampak positif pada peningkatan pengelolaan sungai oleh masyarakat. Pengetahuan yang telah dimiliki diharapkan dapat ditularkan dan menjadi contoh bagi masyarakat di sekitar Kabupaten Maros.
\end{abstract}

Kata Kunci: Sekolah Sungai; Sempadan Sungai;Pengendalian Banjir; Peraturan; Masyarakat.

\begin{abstract}
Maros Regency is one of the regencies in South Sulawesi Province whose river management system is not optimal yet. Based on this case, the Maros River flooding problem in Maros Regency must be dealt with as soon as possible in a good and correct manner and community participation is needed in terms of understanding river border regulations. The purpose of this activity is to provide socialization to the community to increase community knowledge about river border regulations. The method is used to achieve the stated goals and targets is to carry out river schools which are expected to be useful for the local community. Activities undertaken will involve the community. The implementation of this community service activity, in the form of socialization of river boundary regulations in the context of flood control, is expected that community knowledge about river border will increase and patterns of community behavior regarding the handling of river border areas can be increased and will have a positive impact on improving river management by the community. The knowledge that is possessed is expected to be transmitted and become an example for the community around Maros Regency.
\end{abstract}

Keywords: River School; Sempadan River; Flood Control; Regulations;Community.

\section{Pendahuluan}

Kabupaten Maros merupakan salah satu kabupaten di Provinsi Sulawesi Selatan yang sistem pengelolaan sungainya belum maksimal. Berdasarkan hal ini, maka permasalahan banjir di Sungai Maros Kabupaten Maros harus ditangani sesegera mungkin dengan cara yang baik dan benar serta diperlukan partisipasi masyarakat dalam hal pemahaman peraturan daerah sempadan sungai. 
Berdasarkan analisis situasi dan pengamatan dilapangan serta hasil diskusi dengan beberapa anggota masyarakat, diketahui bahwa permasalahan utama yang dialami masyarakat secara umum adalah sebagai berikut:

1. Kepedulian menjaga kebersihan lingkungan sungai dan pengetahuan masyarakat tentang pengelolaan sungai yang baik dan benar masih rendah.

2. Persentase sosialisasi/penyuluhan mengenai sungai dan peraturan daerah sempadan sungai masih rendah.

Penanganan permasalahan dilakukan dengan cara memberikan sosialisasi peraturan daerah sempadan sungai dalam rangka pengendalian banjir.

Secara garis besar, solusi yang akan ditawarkan untuk mengatasi permasalahan tersebut di atas adalah sebagai berikut: memberikan sosialisasi kepada masyarakat untuk meningkatkan pengetahuan masyarakat tentang peraturan daerah sempadan sungai. Kegiatan yang dilakukan akan melibatkan dan mengikut sertakan masyarakat sehingga nantinya akan terbiasa dalam proses pengelolaan sungai.

Rencana kegiatan yang akan dilakukan adalah sosialisasi yang diharapkan berguna bagi masyarakat setempat. Kegiatan sosialisasi meliputi penyampaian kepada masyarakat atau sosialisasi mengenai pentingnya pemahaman akan peraturan tentang daerah sempadan sungai.

Adanya sosialisasi peraturan daerah sempadan sungai dalam rangka pengendalian banjir maka diharapkan pola prilaku masyarakat mengenai penanganan daerah sempadan sungai dapat ditingkatkan dan akan memberikan dampak positif pada peningkatan pengelolaan sungai oleh masyarakat.

\section{Latar Belakang Teori}

Kini gencar-gencarnya dilakukan sekolah sungai di Indonesia oleh komunitas-komunitas pecinta sungai. Sekolah sungai mulai menjangkau pelosok dan banyak orang bersemangat untuk mengembangkannya. Beberapa Konsep dasar sekolah sungai yang dapat dikembangkan bersama, diantaranya adalah : 1) otonom, masing-masing bebas mengembangkannya baik manajemen maupun kurikulum. UNHAS, UGM, dan PUPR selama ini membantu memberikan referensi modul dan model pelaksanaan sekolah sungai, 2) berefek langsung dan jangka panjang, sebaiknya ada praktek langsung untuk gerakan restorasi sungai sehingga sungai menjadi bersih, sehat, aman, lestari, produktif dan bermanfaat bagi semua, 3) partisipatif, sebanyakbanyaknya mengajak semua beraksi bersama dan memahami kebutuhan yang bottom up bukan top down.

Dalam rangka mengapdating konsep dasar dari sekolah sungai maka kami dari Kelompok Keahlian Dosen Departemen Sipil Unhas yang telah membentuk Komunitas Peduli Sungai Unhas tergerak melakukan segala bentuk aktivitas untuk peningkatan pemahaman akan sungai dengan segala fenomenanya kepada masyarakat. Salah satu fenomena krusial yang menimbulkan masalah besar adalah terjadinya banjir di sungai.

\section{Metode}

Daerah yang menjadi target pelaksanaan kegiatan adalah Kabupaten Maros. Alasan pemilihan didasari karena daerah tersebut belum mendapatkan pemahaman sekolah sungai, utamanya pemahaman peraturan daerah sempadan sungai. 
Metode pendekatan untuk menyelesaikan permasalahan yang dihadapi masyarakat dengan cara melaksanakan Sekolah Sungai berupa "Sosialisasi Peraturan Daerah Sempadan Sungai dalam Rangka Pengendalian Banjir", tepatnya di Sungai Maros, Kabupaten Maros. Kegiatan Pengabdian masyarakat dilaksanakan melalui 2 tahapan yaitu tahap persiapan dan tahap pelaksanaan kegiatan. Prosedur persiapan dan pelaksanaan kegiatan untuk mewujudkan solusi yang ditawarkan dilaksanakan secara bersama anggota tim pengusul dengan mitra.

1. Tahap persiapan meliputi kegiatan: a)pembentukan tim yang dilanjutkan dengan rapat untuk menentukan tema, lokasi dan mitra kerjasama, b)koordinasi dengan pihak mitra untuk mendiskusikan permasalahan yang utama yang dihadapi masyarakat dan solusi yang ditawarkan untuk menyelesaikan permasalahan tersebut serta memilih pendekatan untuk merealisasikan solusi yang telah disepakati, dan c)survey pendahuluan ke lokasi yang menjadi target pelaksanaan kegiatan dan rapat persiapan tim untuk membuat usulan pengabdian masyarakat.

2. Tahap Pelaksanaan meliputi kegiatan: a)penyampaian undangan dan persiapan tempat pelaksanaan kegiatan berserta penyediaan alat dan bahan yang akan digunakan, b)kegiatan sekolah sungai untuk menjelaskan materi mengenai persyaratan sempadan sungai, dasar pertimbangan dan dasar hukum, dan kriteria penetapan garis sempadan c)kegiatan umpan balik dari masyarakat.

Keberhasilan pelaksanaan kegiatan sangat ditentukan oleh kerjasama antara anggota tim pengusul dengan mitra. Partisipasi mitra diwujudkan dalam penyampaian informasi mengenai permasalahan yang dihadapi oleh masyarakat setempat dan menjadi fasilitator yang menghubungkan antara tim pengusul pengabdian masyarakat dari Universitas Hasanuddin dengan masyarakat.

Keberlanjutan program sangat diharapkan guna terciptanya pengelolaan sungai yang baik dan benar bagi seluruh masyarakat di Kabupaten Maros. Besar harapan keberlanjutan program ini agar masyarakat akan terbiasa dalam proses pengelolaan sungai.

\section{Hasil dan Diskusi}

Pengetahuan yang ditransferkan kepada masyarakat adalah yang terkait dengan peraturan Menteri Pekerjaan Umum dan Perumahan Rakyat no 28 tahun 2015 tentang sempadan sungai dan danau. Kegiatan pengabdian ini dilaksanakan di Kabupaten Maros selama 1 hari yang dihadiri sekitar 40 orang peserta.

Kegiatan sekolah sungai ini dilaksanakan dengan tujuan untuk meningkatkan pengetahuan dan pemahaman masyarakat mengenai sempadan sungai, persyaratan sempadan sungai, dasar pertimbangan dan dasar hukumnya, dan kriteria penetapan garis sempadan. Kegiatan sekolah sungai ini diawali dengan sambutan oleh aparat pemerintah di Kabupaten Maros kemudian dilanjutkan dengan penyajian materi oleh tim pengabdian. Rangkaian akhir dari kegiatan penyuluhan adalah diskusi atau tanya jawab. Pelaksanaan kegiatan sekolah sungai secara lengkap tersaji pada gambar berikut: 


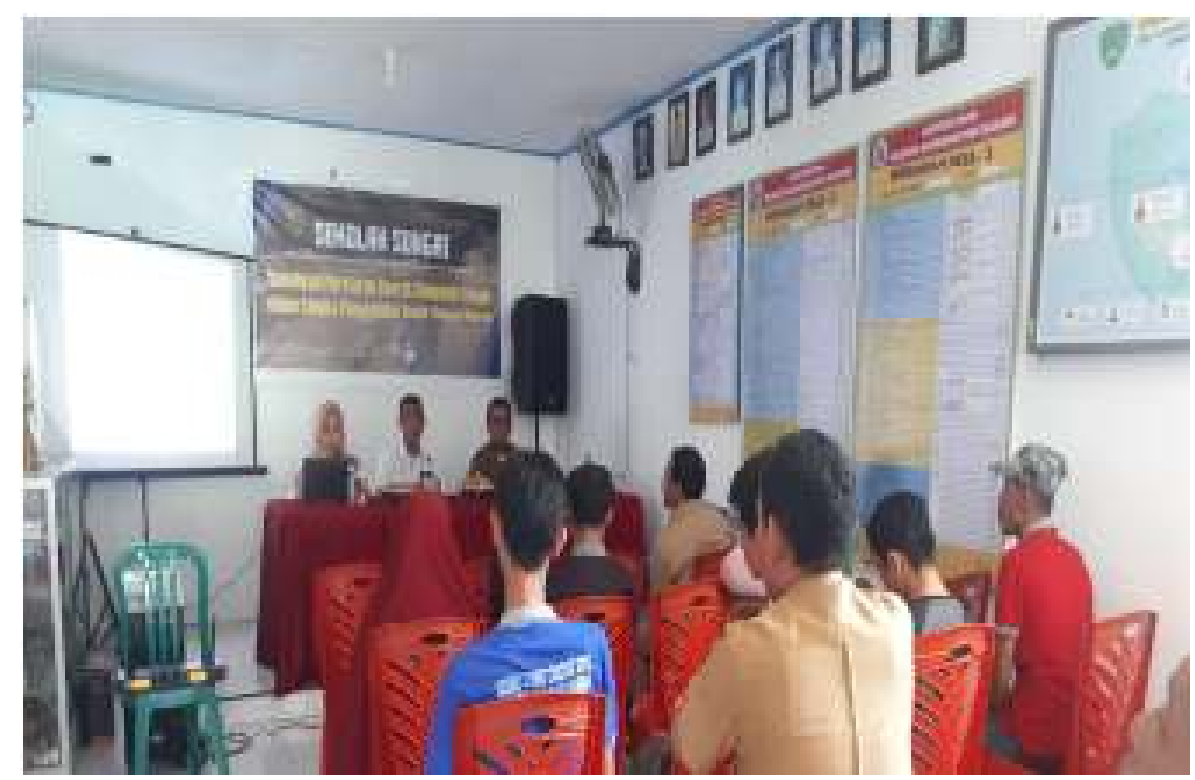

Gambar 1. Sambutan Aparat Pemerintah Kabupaten Maros

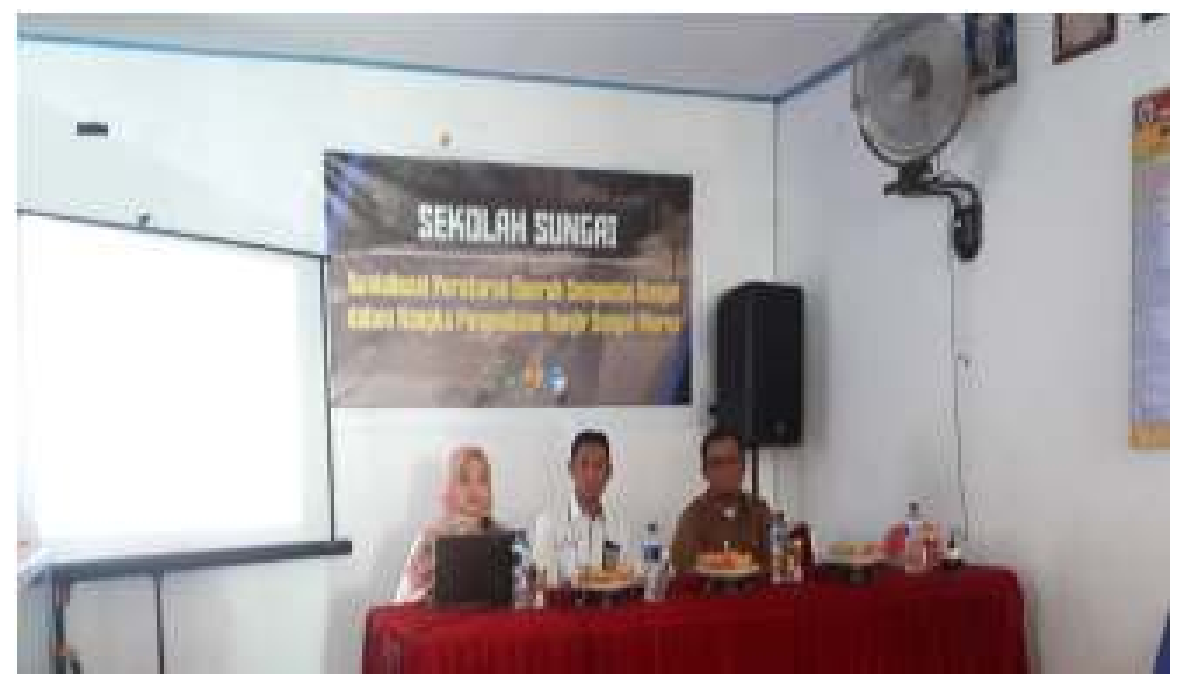

Gambar 2. Pemaparan Materi oleh Tim PKM 


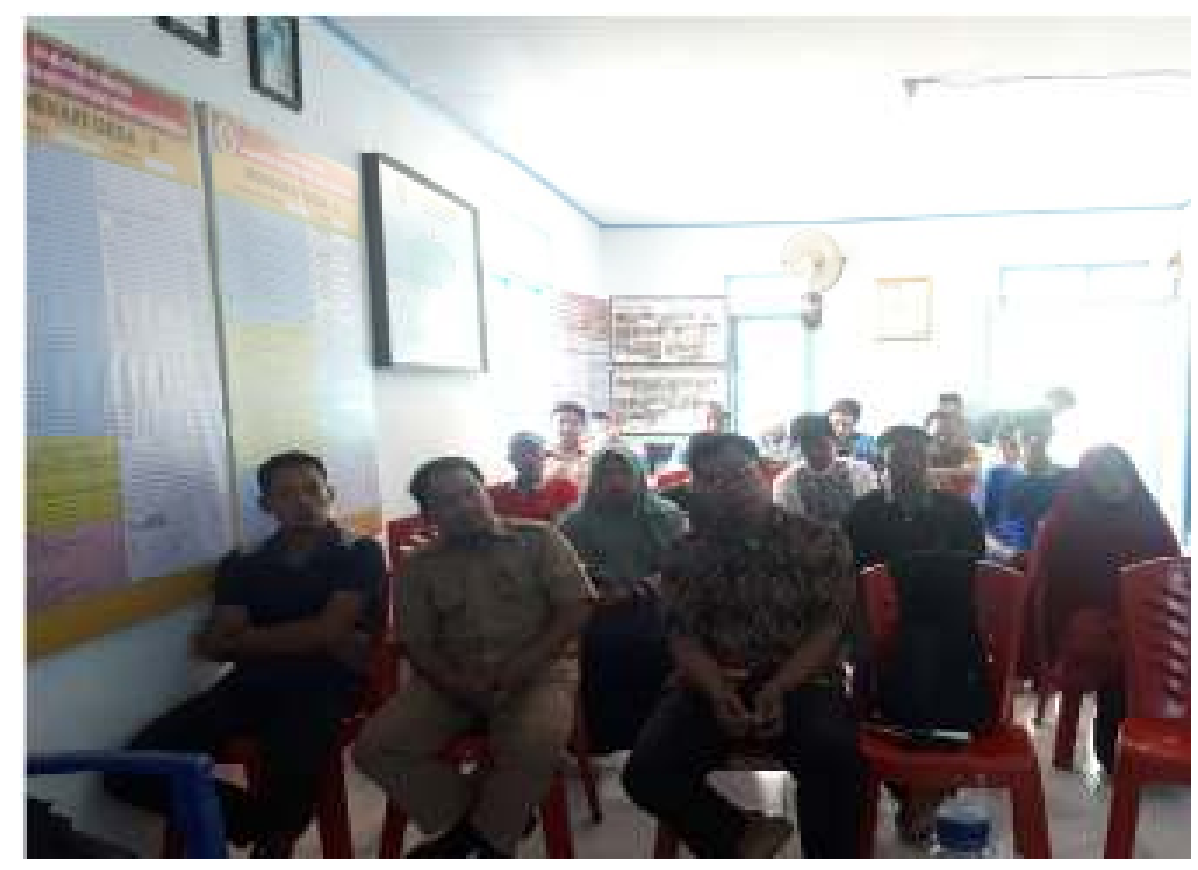

Gambar 3. Peserta Kegiatan PKM

Kegiatan sekolah sungai ini bertujuan untuk: 1) meningkatkan pengetahuan komunitas peduli sungai dan masyarakat di Kabupaten Maros, 2) mendapatkan peningkatan kapasitas Sumber Daya Manusia (SDM) dalam pengelolaan Sumber Daya Air, dan 3) agar komunitas peduli sungai dan masyarakat dapat mengetahui batas-batas sempadan sungai sebagai fungsi sungai dan wadah air yang perlu dijaga bersama.

Garis sempadan sungai dan danau, dimaksudkan sebagai upaya agar kegiatan perlindungan, penggunaan dan pengendalian atas sumber daya yang ada pada sungai dan danau dapat dilaksanakan sesuai tujuannya. Penetapan garis sempadan sungai dan garis sempadan danau bertujuan agar; a) fungsi sungai dan danau tidak terganggu oleh aktifitas yang berkembang disekitarnya, b) kegiatan pemanfaatan dan upaya peningkatan nilai manfaat sumber daya yang ada di sungai dan danau dapat memberikan hasil secara optimal sekaligus menjaga kelestarian fungsi sungai dan danau, c) menjaga daya rusak air sungai dan danau terhadap lingkungannya dapat dibatasi pada kanan dan kiri sempadan sungai, dan d) sebagai upaya melindungi agar fungsi sungai dapat berlangsung secara berkelanjutan, bagi kehidupan manusia, sebagai penyedia air dan wadah air untuk memenuhi kebutuhan rumah tangga, air baku, industri, parawisata, olahraga. transportasi, pertahanan, perikanan, pembangkit tenaga listrik, dan kebutuhan lainnya (Pasal 3).

Kriteria penetapan garis sempadan (Pasal 4); 1) sempadan sungai meliputi ruang di kiri dan kanan palung sungai antara garis sempadan dan tepi sungai untuk sungai tidak bertanggul, 2) diantara garis sempadan dan tepi luar kaki tanggul untuk sungai bertanggul, 3) garis sempadan sebagaimana yang dimaksud ditentukan pada ; a) sungai tidak bertanggul di dalam kawasan perkotaan, b) sungai tidak bertanggul di luar kawasan perkotaan, c) sungai bertanggul di dalam kawasan perkotaan, d) sungai bertanggul di luar kawasan perkotaan, e) sungai yang terpengaruh pasang air laut dan f) sungai yang terpengaruh oleh mata air. 
Garis sempadan pada sungai tidak bertanggul di dalam kawasan perkotaan yang dimaksud dalam (pasal 5) ditentukan ; a) paling sedikit berjarak 10 meter dari tepi kiri dan kanan palung sungai sepanjang alur sungai, dalam hal kedalaman sungai kurang dari atau sama dengan 3 meter, b) paling sedikit berjarak 15 meter dari tepi kiri dan kanan palung sungai sepanjang alur sungai, dalam hal kedalaman sungai lebih dari 3 meter sampai dengan 20 meter dan c) paling sedikit berjarak 30 meter dari tepi kiri dan kanan palung sungai sepanjang alur sungai, dalam hal kedalaman dari 20 meter.

Garis sempadan sungai yang tidak bertanggul di luar kawasan perkotaan sebagaimana yang dimaksud dalam (pasal 6) ditentukan ; a) sungai besar dengan luas DAS (Daerah aliran sungai) < $500 \mathrm{~km}^{2}$, maka garis sempadan sungai berjarak 100 meter dari tepi kiri dan kanan palung sungai sepanjang alur sungai, b) sungai kecil dengan luas DAS (Daerah Aliran Sungai) $\geq 500 \mathrm{~km}^{2}$ maka garis sempadan sungai berjarak 50 meter dari tepi kiri dan kanan palung sungai sepanjang alur sungai, dapat dilihat pada Gambar 4.

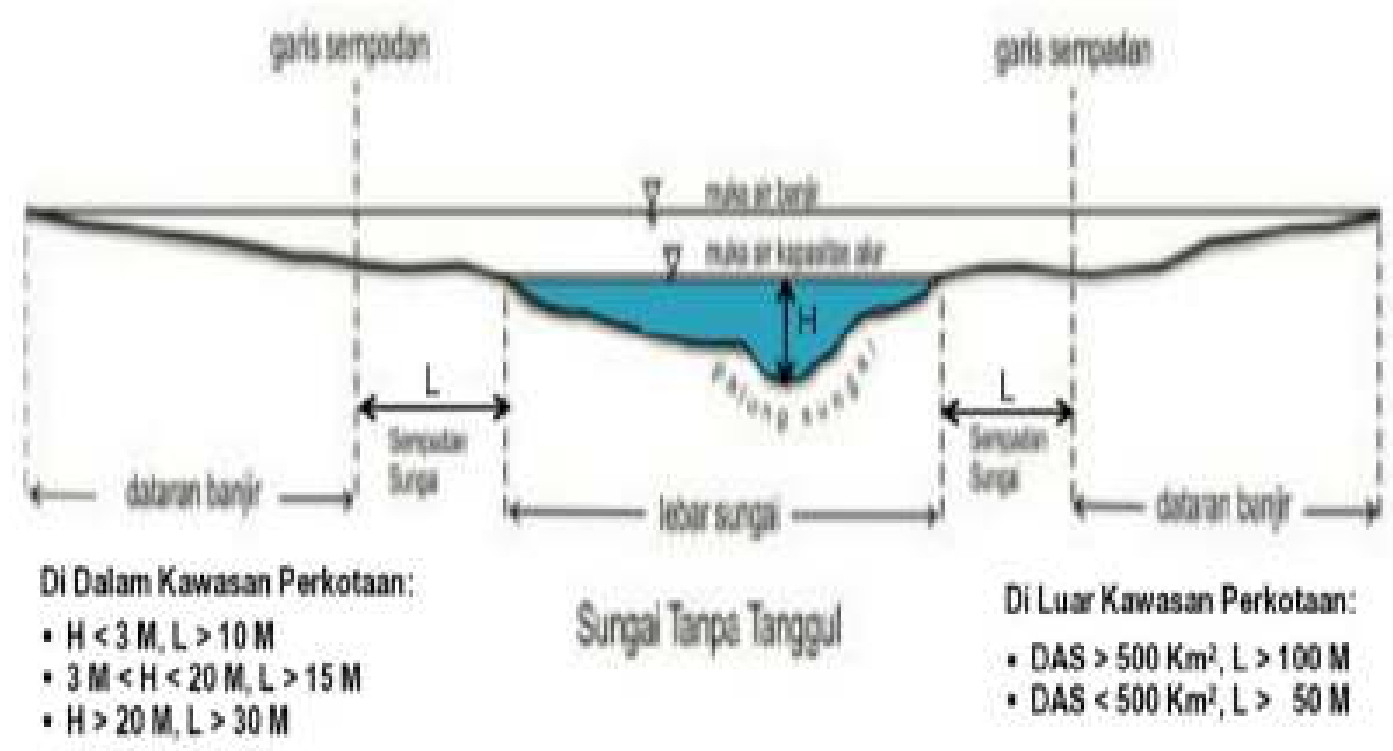

Gambar 4. Garis Sempadan Sungai yang Tidak Bertanggul Di Luar Kawasan Perkotaan

Garis sempadan sungai yang bertanggul di dalam kawasan perkotaan sebagaimana yang dimaksud dalam (pasal 7) ditentukan, paling sedikit berjarak 3 meter dari tepi luar kaki tanggul sepanjang alur sungai. Garis sempadan sungai yang bertanggul di luar kawasan perkotaan sebagaimana yang dimaksud dalam (pasal 8) ditentukan sedikit berjarak 5 meter dari tepi luar kaki tanggul sepanjang alur sungai, dapat dilihat pada Gambar 5. 


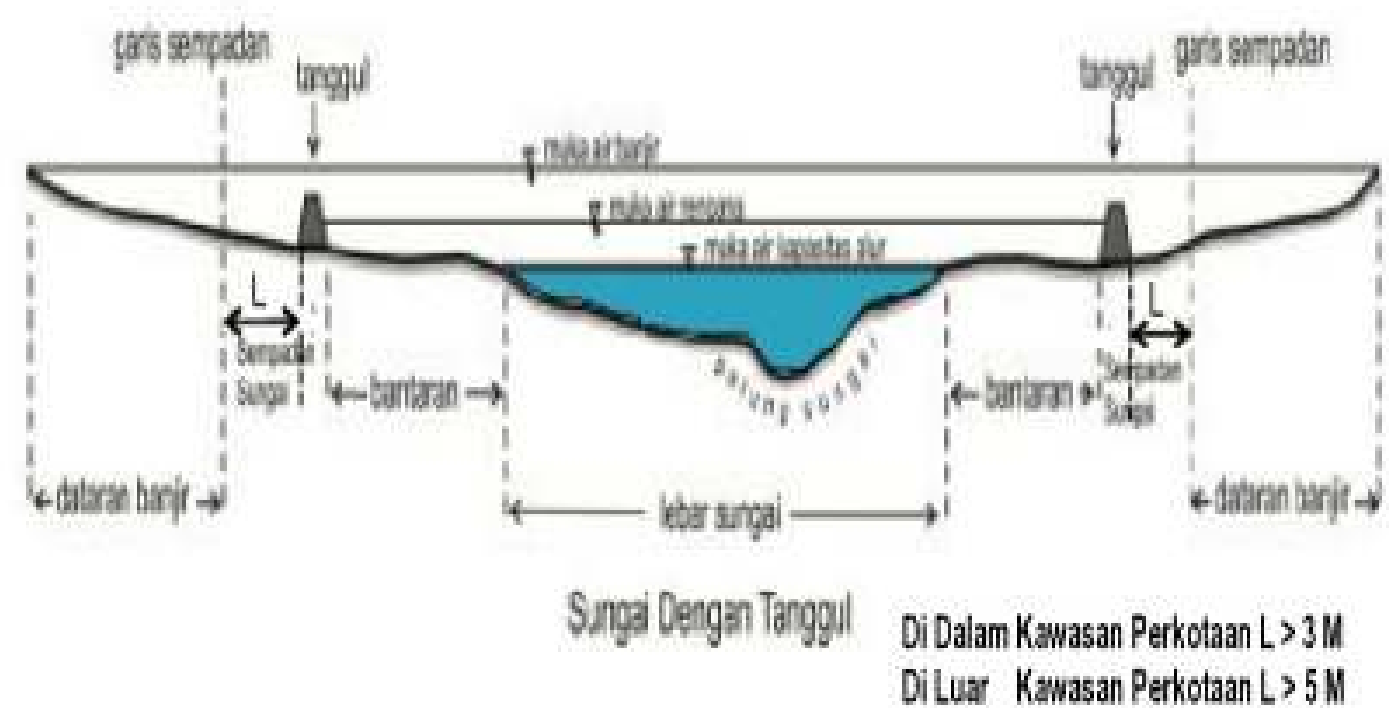

Gambar 5. Garis Sempadan Sungai yang Bertanggul Di Dalam Kawasan Perkotaan

Dalam hal di dalam sempadan sungai terdapat tanggul untuk mengendalikan banjir, ruang antara tepi palung sungai dan tepi dalam kaki tanggul merupakan bantaran sungai yang berfungsi sebagai ruang penyalur, banjir (Pasal 9). Penentuan garis sempadan sungai yang terpengaruh pasang air laut sebagaimana dimaksud, dilakukan dengan cara yang sama dengan penentuan garis sempadan sungai sesuai pada pasal 5,6,7 dan 8 yang diukur dari tepi muka air pasang ratarata (pasal 10).

Bila terdapat bangunan dalam sempadan sungai, maka bangunan tersebut dinyatakan dalam status quo dan secara bertahap harus ditertibkan untuk mengembalikan fungsi sempadan sungai, namun tidak berlaku bagi bangunan yang terdapat dalam sempadan sungai untuk fasilitas kepentingan tertentu meliputi ; a) bangunan prasarana sumber daya air, b) fasilitas jembatan dan dermaga, c) jalur pipa gas dan air minum, d) rentangan kabel listrik dan telekomunikasi dan e) bangunan ketenagalisrikan (Pasal 15).

Kriteria Penetapan lebar sempadan sungai, mata air dan danau menurut Permen PUPR 28/2015 bisa dilihat pada Tabel 1 dan Tabel 2. 
Tabel 1. Kriteria Penetapan lebar sempadan sungai menurut Permen PUPR 28/2015

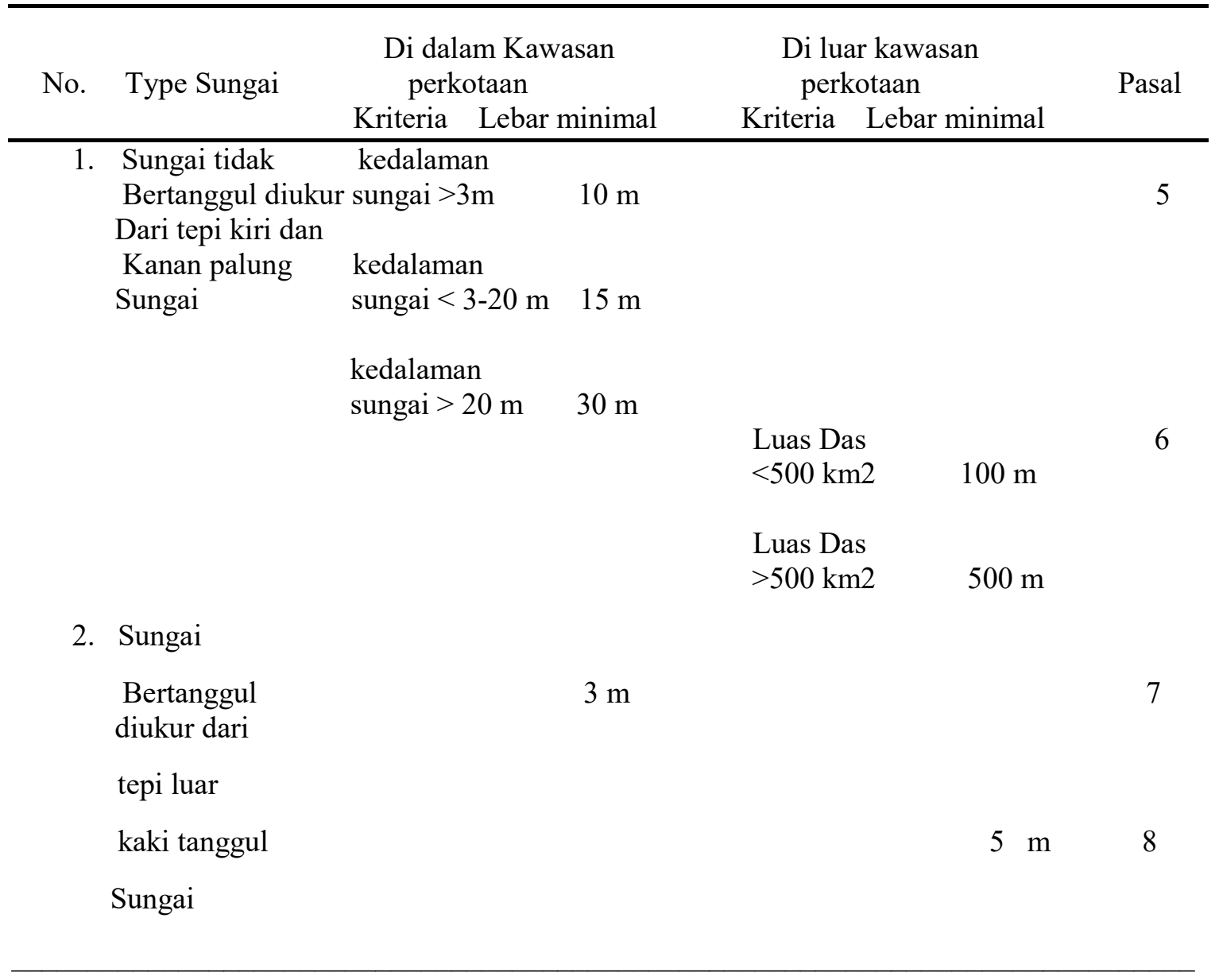

Tabel 2. Kriteria Penetapan lebar sempadan mata air dan danau menurut Permen PUPR 28/2015

\begin{tabular}{|c|c|c|c|c|c|}
\hline \multirow{2}{*}{ No. } & \multirow{2}{*}{ Type Sempadan } & \multicolumn{2}{|c|}{ Mengelilingi mata air } & \multicolumn{2}{|l|}{ Mengelilingi danau } \\
\hline & & Kriteria & Lebar minimal & Kriteria Lebar minimal & \\
\hline 1. & $\begin{array}{l}\text { Garis sempadan } \\
\text { Mata air }\end{array}$ & $\begin{array}{l}\text { Diukur } \\
\text { dari pusat } \\
\text { Mata air }\end{array}$ & $200 \mathrm{~m}$ & & 11 \\
\hline 2. & $\begin{array}{l}\text { Garis sempadan } \\
\text { Danau }\end{array}$ & & & $\begin{array}{l}\text { Diukur dari } \\
\text { tepi muka air } \\
\text { Tertinggi } \\
\text { yang pernah } \\
\text { terjadi }\end{array}$ & \\
\hline
\end{tabular}

\section{Kesimpulan}

Pelaksanaan kegiatan sekolah sungai berkontribusi pada peningkatan pengetahuan dan pemahaman masyarakat mengenai peraturan daerah sempadan sungai. Berbekal kemampuan 
pengetahuan dan pemahaman yang ditularkan oleh tim PKM UNHAS, diharapkan pola prilaku masyarakat mengenai penanganan daerah sempadan sungai dapat diterapkan dan memberikan dampak positif pada peningkatan pengelolaan sungai oleh masyarakat, demi tercapainya sungai yang bersih, sehat, berkelanjutan dan tidak lagi mengalami banjir.

\section{Ucapan terima kasih}

Ucapan terima kasih kepada Fakultas Teknik Unhas untuk dukungan dana pelaksanaan kegiatan Program Kemitraan Masyarakat (PKM) Universitas Hasanuddin, dana DRPM 2019 dan kepada Kepala Dinas PUPR Kabupaten Maros dan jajaran staf desa yang telah memfasilitasi pelaksanaan kegiatan ini serta turut serta mendorong keaktifan masyarakat dalam kegiatan ini.

\section{Daftar Pustaka}

Gunawan, (2007). Pengembangan Daerah Riparian di Badan Sungai dengan Pengembangan Konsep EkoHidrologi. ITB Press. Bandung.

Peraturan Pemerintah Republik Indonesia Nomor 35 (1991) Tentang Sungai.

Peraturan Menteri PUPR Republik Indonesia Nomor 28 (2015) Tentang Sempadan Sungai dan Danau.

Undang-Undang Nomor 11 (1974) Tentang Sungai.

Undang-undang Nomor 17 (2019) Tentang Sumber Daya Air. 